

\title{
BJMHR
}

British Journal of Medical and Health Research

Journal home page: www.bjmhr.com

\section{Diagnostic Utility of Complexed Prostate-specific Antigen in the Early Detection of Prostate Cancer in Nigerian Men.}

\author{
Eyam SundayEyam ${ }^{1}$, Edet E. Ikpi ${ }^{2,3}$, Egbuagha Ephraim $\mathbf{U}^{4}$, Okhormhe Zibril A ${ }^{\mathbf{1}}$, \\ Azinge Elaine Chinyelu $\mathbf{4}^{4}$, Bolarin Debayo $\mathbf{M}^{\mathbf{1}}$ \\ 1.Department of Chemical Pathology, University of Calabar. Calabar, Nigeria. \\ 2.Departments of Urology, University of Calabar, Calabar, Nigeria. \\ 3.Department of Surgery, JFK Memorial Hospital, Monrovia, Liberia \\ 4.Department of Clinical Pathology, Lagos University Teaching Hospital, Lagos
}

\section{ABSTRACT}

We evaluate the diagnostic utility of complexed prostate-specific antigen (cPSA) in the early biochemical detection of Prostate Cancer among Nigerian men in Calabar. This was a cross sectional descriptive study involving one hundred and twenty (120) male participants, in two groups of sixty, consecutively recruited from the Urology clinic within a one year period following approval from the Health Research Ethics Committee of the University of Calabar Teaching Hospital. The first group of sixty (60) of the patients were clinically and histologically confirmed to have prostate cancer $(\mathrm{PCa})$ and were treatment naive. While the second group of sixty (60) patients also clinically and histologically confirmed to have benign prostatic hyperplasia (BPH) were used as controls. Participants were between 50 and 80 years old. Sera were analyzed for complexed and total PSA using WKEA ELISA kits and read with STAT FAX 2100 micro plate reader. Values of complexed PSA were higher in prostate cancer than in $\mathrm{BPH}$, with median values of $15.8 \mathrm{ng} / \mathrm{mL}$ and $0.9 \mathrm{ng} / \mathrm{mL}$, respectively $(\mathrm{P}=.001)$. Similarly, median values of total PSA were higher in PCa $(19.3 \mathrm{ng} / \mathrm{mL})$ than in $\mathrm{BPH}(8.4 \mathrm{ng} / \mathrm{mL}), \mathrm{P}=.001$. Receiver operating characteristic curve (ROC) analyses showed area under the curve (AUC) for cPSA to be 0.575 , with a sensitivity of $56 \%$ and specificity of $62.7 \%$ at a cutoff of $1.0 \mathrm{ng} / \mathrm{mL}$, while tPSA had AUC of 0.735 , sensitivity of $75.7 \%$ and specificity of $64.4 \%$ at a different and higher cutoff above $10.0 \mathrm{ng} / \mathrm{mL}$. Complexed and total prostate-specific antigen (PSA) though both sensitive and specific for the biochemical prediction of prostate cancer have some variability with Complexed PSA being an early predictor of prostate cancer than total PSA. This is because complexed PSA was able to detect prostate cancer at very low cutoff value $(1.0 \mathrm{ng} / \mathrm{mL})$ when compared to tPSA that was able to detect prostate cancer at a higher cutoff value (>10.0 ng/mL) among Nigerian men. Therefore, complexed PSA is a good biomarker for early biochemical prediction of prostate cancer disease in Nigerian African men when total PSA levels are subclinical.

Keywords: Complexed PSA, total PSA, early diagnosis, prostate cancer, Nigerian men. 


\section{INTRODUCTION}

In spite of rising cases of prostate cancer in our environment, there is still much difficulty in making early prediction and diagnosis due to prevailing discordances with clinical findings and poor performance characteristics of available assay methods. For over three decades, prostate-specific antigen (PSA) has been at the centre of diagnosis of prostate disorders but is not disease specific. ${ }^{1,2}$ There is considerable overlap in values of PSA in malignant and benign prostate diseases as alluded to by some studies among Nigerian men with $\mathrm{PCa} .{ }^{2}$, ${ }^{3}$ Biopsy is considered the gold standard for prostate cancer diagnosis and appropriate patient selection for biopsy is dependent on the total PSA value. However, the threshold at which total PSA values informs biopsy are unclear. ${ }^{2}$ In other to improve the performance of PSA towards being disease specific, several modalities have been employed such as PSA density, ${ }^{4}$ and PSA velocity but lack clinical relevance. The traditional use of free PSA when digital rectal examination (DRE) is negative and PSA is in the gray zone has led to unnecessary biopsies with associated side effects of the procedure. Other techniques like prostate health index have also been used but are expensive and cumbersome, involving at least three analytes to establish a mathematical relationship necessary for the calculation to be done. Complexed PSA has been shown to be more specific as a single analyte to detect prostate cancer in non-African men. ${ }^{1}$ However, differences in most analyte concentrations have been noted across racial diversities, as well as differences occurring with changes in dietary and environmental conditions globally. ${ }^{5}$ In Nigeria, free PSA and complexed PSA are not routinely assayed for in the laboratories ${ }^{2}$, due to laboratory economics, clinician factor, and widespread poverty. Nigerian men are known to seek medical attention late ${ }^{4}$ and often present with complications, hence, having real-time accurate and specific diagnosis at presentation is desirable. In the majority of the prostate cancer patients with late presentation to specialist urology clinics in Nigeria, the commonest complaint has been that of being unable to afford the cost of investigations. This supports the need to identify a more disease specific biomarker to reduce the cost burden on patients and turnaround time of making accurate diagnosis. This study is also pertinent to draw the attention of clinicians towards availing the Nigerian populace the opportunity to be properly evaluated, diagnosed early, and avoid unnecessary biopsies. Complexed PSA has been proposed as a candidate marker with high specificity for early prostate cancer detection in western populations. ${ }^{1}$ Considering the above confounders and the prospect of complexed PSA, the need to determine the diagnostic utility of complexed PSA among native African population is timely, hence, the analytic performance characteristics of complexed PSA and total PSA were compared in treatment 
naive, histologically confirmed prostate cancer and BPH patients among Nigerian men in Calabar.

\section{MATERIALS AND METHOD}

The study was cross sectional descriptive and conducted within a period of 12 months. It involved 60 treatment naive male patients histologically confirmed to have prostate cancer and 60 treatment naïve $\mathrm{BPH}$ patients as controls, within the age range of 50-80 years. The participants were consecutively recruited from the urology clinic of the University of Calabar Teaching Hospital, Calabar. Multi-sampling needles and vacutainers were employed to collect $4 \mathrm{~mL}$ of blood samples from the patients before any manipulative procedures of the prostate were done. The samples were separated within an hour of collection and the sera served in aliquots into cryotubes and stored at $-80^{\circ} \mathrm{C}$ before analyses. Analysis was done using WKEA ELISA kits, lot number 20150706, for complexed and total PSA, and was read off with STAT FAX 2100 micro plate reader at an absorbance of 450nM.

\section{RESULTS AND DISCUSSION}

Median Total PSA values were statistically significantly higher in the PCa group of patients compared to the BPH control group $19.3(10.6 \mathrm{ng} / \mathrm{mL}-72.5) \mathrm{ng} / \mathrm{mL}$ and $8.4(3.8-15.0) \mathrm{ng} / \mathrm{mL}$ respectively and $\mathrm{P}<0.001$.

Median Complexed PSA values were also statistically significantly higher in the PCa group of patients compared to the BPH control group $15.8(7.7-40.1) \mathrm{ng} / \mathrm{mL}$ and $0.9(0.5-1.2) \mathrm{ng} / \mathrm{mL}$ respectively and $\mathrm{P}=0.001$.

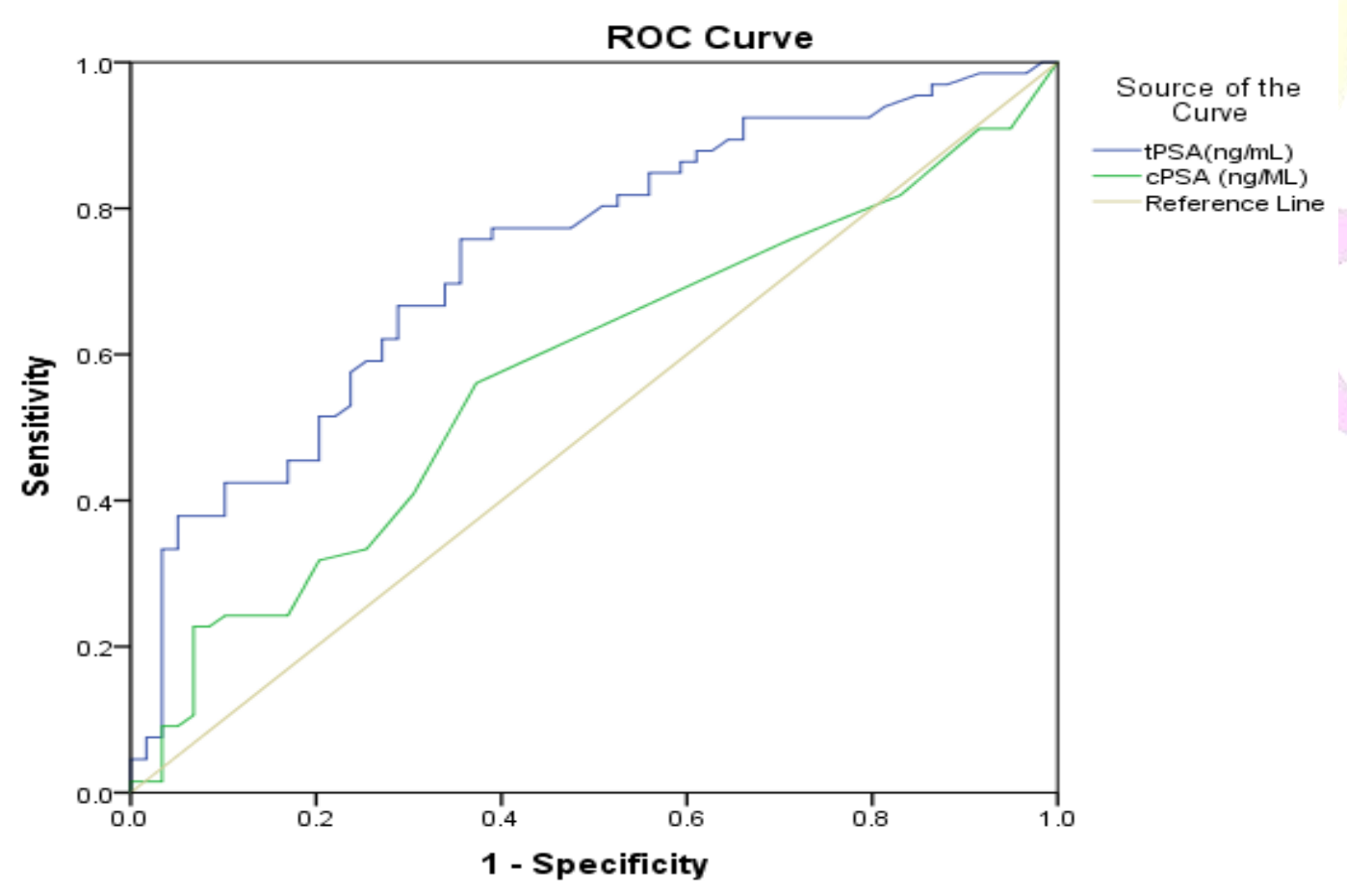




\section{Figure 1: ROC comparing performance characteristics of complexed PSA and total} PSA.

Receiver operating characteristic (ROC) curve analysis of tPSA and cPSA showed that tPSA had area under the curve (AUC) of 0.735 at a cutoff above $10.0 \mathrm{ng} / \mathrm{ml}(>10.0 \mathrm{ng} / \mathrm{ml})$ with specificity and sensitivity of $64.4 \%$ and $75.7 \%$, respectively, compared to complexed PSA with AUC of 0.575 at a cutoff of $1.0 \mathrm{ng} / \mathrm{ml}(1.0 \mathrm{ng} / \mathrm{ml})$ and specificity and sensitivity of $62.7 \%$ and $56.0 \%$ respectively, as shown in figure 1 .

Total prostate specific antigen (tPSA) estimation has been the mainstay analyte used in the biochemical prediction, detection and monitoring of prostate diseases, and its values inform the urologist's decision to proceed to perform biopsy, which is the gold standard for diagnosis of prostate cancer. This has been fraught with inconsistencies due to its overlap in the various prostate disorders, and has led to unnecessary biopsies being performed in our environment because of the use of wrong decision limits, hence wrong patient selection for biopsy. ${ }^{6}$ Total prostate specific antigen (tPSA) is a prostate-specific biochemical marker but it is not disease-specific, as has been demonstrated by many studies and corroborated in this study. Overall, median tPSA concentration was high in both the test group and the control group of patients in reference to conventional cutoffs for decision making. There was however statistically significantly higher median concentrations of tPSA in patients with prostate cancer than in the control group with benign prostatic hyperplasia $(\mathrm{BPH})^{7,8}$ Comparatively, median concentration of complexed prostate specific antigen (cPSA) was also statistically significantly higher in PCa patients than in the control group of patients. This was in conformity with other studies done in Western climes. ${ }^{1,7,9}$ In terms of optimal performance characteristics of sensitivity and specificity in the detection of prostate cancer using cutoff point, this study showed that at a lower cutoff point value of $1.0 \mathrm{ng} / \mathrm{mL}$, cPSA was more sensitive and specific in detecting prostate cancer compared to tPSA that was more sensitive and specific at a higher cutoff point value above $10.0 \mathrm{ng} / \mathrm{mL}$. This suggest that early in prostate cancer when cPSA and tPSA are still being expressed in low concentrations, cPSA being highly sensitive and specific at this point would be demonstrated in plasma and therefore could aid early detection of PCa in native African men. This was in agreement with the work done in Germany in a European population. ${ }^{9}$ This finding of improved specificity of detection of prostate cancer using cPSA at lower cutoff point when compared to tPSA that had better sensitivity and specifity at a higher cutoff point, was suggestive of the fact that cPSA could have diagnostic value in subclinical state of prostate cancer and therefore could be used as a predictive tool to avert advanced disease as against tPSA that had higher sensitivity and specificity at high cutoff point at which point disease would already be in 
advance state. This was in conformity with a multi centre European study and other studies that used Western populations. ${ }^{10,11}$ However; this was in disagreement with a certain study that showed equivalence in diagnostic performance of cPSA and tPSA to detect prostate cancer in a western population. ${ }^{12}$

Table showing Interquartile range (IQR) i.e. 25 th $-75^{\text {th }}$ percentile of tPSA, and cPSA of the study population.

\begin{tabular}{llll}
\hline Variable & $\begin{array}{l}\text { BPH: } \mathbf{N}=\mathbf{6 0} \\
\text { Median (IQR) }\end{array}$ & $\begin{array}{l}\text { PCa: } \mathbf{N}=\mathbf{6 0} \\
\text { Median (IQR) }\end{array}$ & p - Value \\
\hline tPSA & $8.4(3.8-15.0)$ & $19.3(10.6-72.5)$ & $<0.001$ \\
cPSA & $0.9(0.5-1.2)$ & $15.8(7.7-40.1)$ & 0.001 \\
\hline
\end{tabular}

\section{CONCLUSION}

There was no statistical difference in this study in the pattern of diagnostic performance of complexed prostate-specific antigen and total prostate-specific antigen in the detection of prostate cancer disease in native African populations when compared with studies done in western populations. The study also showed that complexed PSA as a single analyte has high sensitivity and specificity at low analyte concentration suggestive of a higher predictive value for early diagnosis of prostate cancer than total prostate-specific antigen at a lower cutoff. This finding is pertinent to reawaken the interest of urologists in Nigeria to properly evaluate and select future PCa patients for confirmation with biopsy. This would significantly reduce unnecessary biopsies resulting from overlap in total PSA values in our environment.

\section{REFERENCES}

1. Brawer MK, Meyer GE, Letran JL, Bankson DD, Morris DL, Yeung KK, et al. Measurement of complexed PSA improves specificity for early detection of prostate cancer. Urology. 1998;52(3):372-378.

2. EL-Sakka A AS, AbdelFattah E, and El-Sarafi T. Serum transforming growth factor beta - 1and prostate-specific antigen as markers for localized and metastatic prostate cancer. African journal of urology. 2004(10):1-8.

3. Abbiyesuku FM, Shittu OB, Oduwole OO, Osotimehin BO. Prostate-specific antigen in the Nigerian African. Afr J Med Med Sci. 2000;29(2):97-100.

4. Iya D CS, Belmonte J, Morris D, Glew RH and Van der Jagt DJA. Prostate sspecific antigen in Africans: a study in Nigerian men. Nigerian journal of surgical research. 2003;5(1 and 2):114-119.

5. Haas GP, Delongchamps N, Brawley OW, Wang CY, de la Roza G. The worldwide epidemiology of prostate cancer: perspectives from autopsy studies. Can J Urol. 2008;15(1):3866-3871. 
6. Wu JT. Assay for prostate specific antigen (PSA): problems and possible solutions. J Clin Lab Anal. 1994;8(1):51-62.

7. Naya Y, Okihara K. Role of complexed PSA in the early detection of prostate cancer. J Natl Compr Canc Netw. 2004;2(3):209-212.

8. Strittmatter F, Stieber P, Nagel D, Fullhase C, Walther S, Stief CG, et al. Detection of prostate cancer with prostate specific antigen and complexed/total PSA: is there any advantage? European Journal of Medical Research. 2011;16(10):445-450.

9. Partin AW, Brawer MK, Bartsche G, Horninger W, Taneja SS, Lepor H, et al. Complexed prostate specific antigen improves specificity for prostate cancer detection: results of a prospective multicenter clinical trial. Journal of Urology. 2003;170(5):1787-1791.

10. Miller MC, O'Dowd GJ, Partin AW, Veltri RW. Contemporary use of complexed PSA and calculated percent free PSA for early detection of prostate cancer: impact of changing disease demographics. Urology. 2001;57(6):1105-1111.

11. Okihara K, Cheli CD, Partin AW, Fritche HA, Chan DW, Sokoll LJ, et al. Comparative analysis of complexed prostate specific antigen, free prostate specific antigen and their ratio in detecting prostate cancer. J Urol. 2002;167(5):2017-2023; discussion 2023-2014.

12. Emeka IU, Ikenna IN, Francis OO, Fred OU, Adesina SO, Samuel RO, et al. Prostatespecific antigen density values among patients with symptomatic prostatic enlargement in Nigeria. World Journal of Surgical Oncology, 2016; 14: 174.

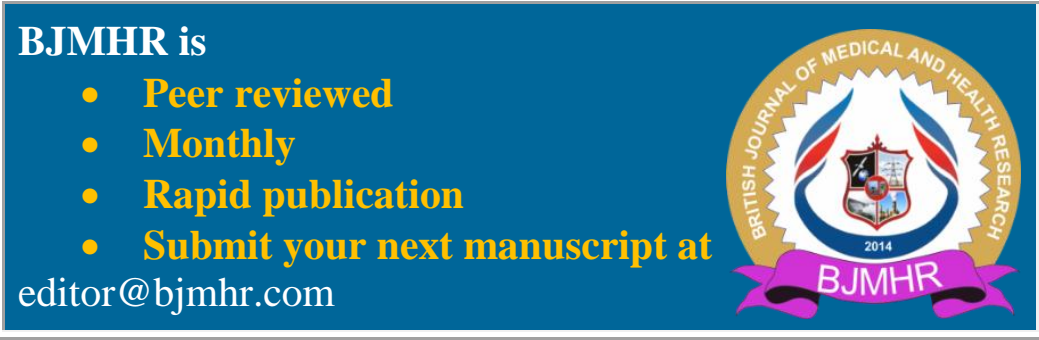

